\title{
Memoria traumática: estrategias de afrontamiento adaptativas e inadaptativas
}

\author{
Traumatic Memories: Adaptive and Maladaptive Coping Strategies
}

\author{
Enrique Echeburúa \\ Universidad del País Vasco (UPv/EHU), Facultad de Psicología. San Sebastián, España. \\ Pedro J. Amor \\ Universidad Nacional de Educación a Distancia (UNED), Facultad de Psicología. Madrid, España.
}

Recibido (10 de abril de 2018) Aceptado (28 de noviembre de 2018)

\begin{abstract}
Resumen
En este artículo se analiza la relación existente entre los recuerdos traumáticos y las posibles estrategias para hacerles frente. Los recuerdos traumáticos son difíciles de integrar en la biografía de las personas afectadas y pueden interferir de forma significativa en su funcionamiento social, académico y profesional. Se distingue psicopatológicamente entre los recuerdos normales y los recuerdos traumáticos. Asimismo se analizan las estrategias de afrontamiento adaptativas, tales como la evitación cognitiva, la exposición terapéutica a los recuerdos traumáticos o la capacidad de perdón. Pero también hay un afrontamiento inadaptativo (nostalgia, sentimientos de odio y de venganza o conductas autodestructivas) que puede dar cuenta de las dificultades de recuperación en algunos pacientes. Por último, se examinan las estrategias de regulación emocional cognitiva y el papel de la resiliencia y del crecimiento postraumático para afrontar los recuerdos traumáticos. Se comentan las implicaciones de este estudio para investigaciones futuras en esta área.

Palabras clave: recuerdos traumáticos; estrategias de afrontamiento adaptativas; afrontamiento inadecuado; resiliencia; crecimiento postraumático.
\end{abstract}

\begin{abstract}
In this paper the relationship between traumatic memories and coping skills to deal with them is analyzed. Traumatic memories are difficult to be integrated into the survivor's life story and can significantly interfere with social, educational and occupational functioning. From a psychopathological point of view, a distinction between normal and traumatic memories is made. Adaptive coping skills to deal with traumatic memories, such as cognitive avoidance, therapeutic exposure to traumatic memories or forgiveness, are analyzed. But there is also maladaptive coping, such as nostalgia, hate and revenge feelings or self-destructive behaviors, which should be taken into account to explain the difficulties of recovery in some patients. Finally, the cognitive emotion regulation strategies and the role of resiliency and post-traumatic growth in some patients to cope with traumatic memories are examined. Implications of this study for future research in this field are commented upon.

Keywords: traumatic memories; adaptive coping skills; maladaptive coping; resiliency; post-traumatic growth.
\end{abstract}

Correspondencia: Enrique Echeburúa. Facultad de Psicología. Universidad del País Vasco (UPV/EHU). Avda. de Tolosa, 70. 20018 San Sebastián (España). E-mail: enrique.echeburua@ehu.eus 


\section{Introducción}

La memoria es la capacidad de fijar, conservar y evocar las vivencias que una persona acumula en su vida. Sin embargo, la codificación de la información no es casi nunca como una grabación fotográfica. Los recuerdos no constituyen una reconstrucción, sino una representación del pasado. La importancia de la memoria radica en que nos permite relacionar el presente con el pasado y proyectar hacia el futuro nuestros pensamientos e ideas (Uzer \& Brown, 2017).

Al margen del olvido generado por la lejanía temporal, los recuerdos influyen y están influidos por las emociones y los sentimientos de la persona. La memoria es, por ello, frágil: se pueden añadir recuerdos de cosas que nunca sucedieron, modificar otros e incluso tergiversarlos por influencia de terceras personas (Mitchell, 2015).

Es decir, la memoria y la afectividad están muy vinculadas. Así, una canción despierta el recuerdo de un amor del pasado y el olor de un bizcocho puede transportar a la infancia porque recuerda a los que preparaba la abuela. Se siente una fuerte emoción cuando una persona trae a la memoria desde el baúl de sus recuerdos acontecimientos que en cierto modo le han marcado de por vida. A nivel psicofisiológico, el hipocampo está estrechamente relacionado con los recuerdos. Sin embargo, los recuerdos de intenso contenido emocional se consolidan en la amígdala en lugar de en el hipocampo (lóbulo temporal) y la corteza frontal. La superproducción de adrenalina durante situaciones de alta emotividad facilita la retención de información. Esto explica por qué la mayoría de la gente se acuerda vívidamente de ciertas experiencias intensas pasadas que han estado cargadas de estrés o de emoción (Kaplan, Levine, Lench, \& Safer, 2016).

La memoria es bastante dependiente del estado de ánimo, pero la relación entre una y otro es de doble sentido. Es decir, los recuerdos pasados alegres o tristes nos pueden producir alegría o tristeza ahora, pero, a su vez, la alegría o tristeza actuales pueden deformar la percepción de nuestros recuerdos y hacer pensar, por ejemplo, que nuestra vida pasada ha sido muy feliz o muy desgraciada (Abend, Pine, Fox \& BarHaim, 2014).

Muchas personas tienen una capacidad de olvidar las cosas desagradables y de recordar las positivas. Es un mecanismo adaptativo de tipo supervivencial. En este caso hay una memoria selectiva de los acontecimientos positivos. Por ejemplo, el divorcio suele ser un proceso doloroso, pero la memoria es selectiva y cada día son más las personas que no dudan en repetir la experiencia de otro emparejamiento (incluso de una boda) (Kuehl, Wolf, Driessen, Schlosser, Fernando \& Wingenfeld, 2017).

El objetivo de este artículo es analizar el procesamiento de la información de los recuerdos traumáticos, así como describir las estrategias de afrontamiento adaptativas y no adaptativas utilizadas por las personas para hacer frente a la memoria del trauma (los recuerdos de los sucesos traumáticos) y precisar cuándo se requiere ayuda terapéutica para modificarlas.

\section{Memoria traumática}

Los sucesos traumáticos, que no son meras adversidades de la vida cotidiana, generan terror e indefensión, ponen en peligro la integridad física o psicológica de una persona y dejan con frecuencia a la víctima en tal situación emocional que es incapaz de afrontarla por sí misma. Cualquier acontecimiento traumático (una agresión sexual, la tortura, la violencia crónica en el hogar, el asesinato de un padre o de una madre, el suicidio de un ser querido, etcétera) supone una quiebra en el sentimiento de seguridad de una persona y una pérdida de confianza básica en las demás personas. El elemento especialmente perturbador es la violencia intencional e injustificada generada por otros seres humanos. Frente a los accidentes, los desastres naturales o las enfermedades las personas suelen resignarse, pero no indignarse (Picó-Alfonso, Echeburúa \& Martínez, 2008).

Las personas cuentan con recursos psicológicos suficientes y con una red de apoyo familiar y social que les permiten hacer frente a las contrariedades habituales en su vida diaria. Pero la intensidad y gravedad del suceso traumático supone una especie de empacho emocional que la víctima es incapaz de digerir por sí misma (Echeburúa, 2010).

No siempre se puede olvidar (como a menudo se pretende en la vida cotidiana) cuando ni cuanto se desea. Borrar de la mente las experiencias negativas ha sido siempre una aspiración humana. Pero los malos recuerdos pueden tener un valor supervivencial para hacer frente a los errores cometidos (reparar sus consecuencias, por ejemplo) o para tomar las medidas adecuadas en el futuro (Cyrulnik, 2013).

Los recuerdos asociados a una carga emocional intensa logran una mejor consolidación en la memoria. Es decir, se recuerda mejor lo que emociona. Pero los recuerdos no se archivan necesariamente en un orden cronológico. En el caso de los sucesos traumáticos, los recuerdos pueden ser imprecisos, formas borrosas que van y vuelven de los lugares recónditos de la memoria. Incluso, cuando se recuerda, se pueden rellenar los huecos con escenas inventadas, como si se hubiesen vivido, para completar el relato y dotarle de una coherencia interna (Abend et al., 2014).

En concreto, las imágenes de un suceso traumático pueden a veces integrarse de una forma caótica y desestructurada en la memoria emocional de la persona e invaden la conciencia de la víctima. De este modo, pueden aparecer pensamientos repetitivos indeseados, pesadillas y alteraciones de la memoria, en forma de relatos fragmentados y desorganizados, o surgir inesperada e incluso inoportunamente 
recuerdos parciales con una gran intensidad emocional. Las imágenes de los sucesos emocionales negativos quedan grabadas a fuego en la memoria icónica de la persona. En estas personas puede haber una hipermnesia afectiva. Los pensamientos invasivos, a modo de recuerdos parásitos, ejercen una tiranía sobre el campo de la conciencia e interfieren negativamente en la adaptación de la persona a la vida cotidiana. Estos pensamientos se refieren a fragmentos significativos de la memoria del trauma, carecen de información contextual, como tiempo y lugar, y su contenido supone una amenaza física o, cuando menos, una amenaza para el sentido del yo (Echeburúa, Amor, Sarasua, Zubizarreta, HolgadoTello \& Muñoz, 2016).

En otras personas, por el contrario, puede surgir una amnesia disociativa (recuerdos incompletos y erráticos, lagunas de memoria, olvido total de la experiencia traumática, etcétera). Es lo que ocurre, por ejemplo, con muchas víctimas adultas que han sufrido abuso sexual en la infancia por parte de un familiar y que tienen dificultades para evocar esos sucesos (pero no otros que han ocurrido en el mismo período de tiempo) por la carga emocional negativa (de vergüenza, de culpa o de odio según los casos) asociada a ellos (De la Cruz, 2017). Es decir, con mucha frecuencia las víctimas recuerdan lo que quieren olvidar y olvidan lo que deben recordar.

Los sucesos traumáticos conllevan una cantidad de información que no puede ser procesada cognitivamente de forma adecuada por la víctima. De este modo, las huellas mnésicas no quedan integradas en los esquemas cognitivos, sino que se vuelven inaccesibles (o difícilmente accesibles) a la conciencia. De hecho, hay personas que, aun con un dolor intenso, necesitan el paso del tiempo para poder evocar los recuerdos traumáticos y reprimen sus recuerdos traumáticos durante años para hacer soportable la vida, ser capaces de amar, tener hijos o concentrarse en un trabajo. De pronto, sin embargo, cuando el esfuerzo que les exige la vida se relaja, pueden ver un día en TV algo que les recuerda lo ocurrido y a partir de ahí los recuerdos no integrados cognitivamente en la memoria verbal comienzan a emerger abruptamente (Echeburúa \& Guerricaechevarría, 2011).

\section{Estrategias de afrontamiento adaptativas}

Más allá de los recursos inmediatos de los que echa mano una persona cuando sufre un suceso traumático (desahogarse emocionalmente en sus familiares o amigos, buscar apoyo social y familiar, concentrarse en el trabajo o distraerse con sus aficiones habituales, etcétera), hay estrategias de afrontamiento que permiten superar a largo plazo el daño emocional sufrido (Tielman, Neerincx, Bidarra, Kybartas \& Brinkman, 2017).

\section{Olvido activo (evitación cognitiva)}

Olvidar es una acción mental involuntaria que consiste en dejar de recordar información previamente adquirida. El desvanecimiento de las huellas mnésicas de las experiencias pasadas (incluidas las negativas) con el paso del tiempo tiene un carácter adaptativo porque permite la inclusión de recuerdos nuevos en relación con acontecimientos más próximos temporalmente. Los viejos recuerdos ceden espacio a otros sucesos recientes que pueden ocupar su lugar en los circuitos cerebrales. De este modo, poder olvidar para los seres humanos es tan importante como poder recordar (Abend et al., 2014).

Las experiencias emocionales intensas son más difíciles de borrar. En estos casos el olvido activo de sucesos traumáticos cargados de dolor o de emociones negativas (vergüenza, odio o culpa) puede ser una reacción protectora natural para mantener el equilibrio emocional. El objetivo del olvido activo es modular emocionalmente el recuerdo. Es decir, para que exista un buen olvido, debe haber una buena memoria. No se trata de un olvido pasivo o amnésico, sino de un olvido activo, que deja de lado los reproches y el deseo de venganza a partir del reconocimiento expreso de la existencia de los hechos ocurridos (Enright \& Fitzigibbons, 2000).

La estrategia adoptada por la persona no es propiamente olvidar, sino echar al olvido, lo que quiere decir que un individuo se acuerda de lo ocurrido y lo tiene presente, pero lo aleja de su conciencia e impide que el pasado determine sus decisiones y vivencias presentes y futuras. Ello significa que la persona se esfuerza activamente por focalizarse atencionalmente en los estímulos presentes y en las expectativas futuras y por no dar pábulo a recuerdos dolorosos. De esta manera, los recuerdos traumáticos se convierten en recuerdos biográficos que no encadenan al individuo al pasado ni le impiden proyectar el futuro. Una cosa es recordar y otra muy distinta vivir recluido en la vivencia de un suceso negativo pasado, lo que genera rencor y amargura (Echeburúa, 2004).

En definitiva, el olvido activo es una forma de evitación cognitiva. Hay veces, sin embargo, en que la evitación puede ser una estrategia contraindicada. En concreto, cuando la persona tiene episodios frecuentes involuntarios de reexperimentación y sufre un nivel alto de irritabilidad, el olvido activo (los intentos por no recordar ni hablar de lo ocurrido) es una estrategia inadecuada. Si la persona padece pesadillas y "flashbacks", se trata de un asunto no cerrado (Foa \& Rothbaum, 1998).

\section{Exposición terapéutica a los pensamientos traumáticos}

Cuando un paciente revive intensamente lo vivido meses $\mathrm{y}$ aun años atrás, significa que hay un procesamiento de la 
Tabla 1. Estrategias de afrontamiento ante sucesos potencialmente traumáticos

\begin{tabular}{|c|c|}
\hline Estrategias inadaptativas & Estrategias adaptativas \\
\hline \multicolumn{2}{|c|}{ Conductual } \\
\hline $\begin{array}{l}\text { Evitación conductual que interfiere negativamente en la } \\
\text { vida cotidiana de la persona }\end{array}$ & $\begin{array}{l}\text { Exposición a situaciones/estímulos que pueden recordarle } \\
\text { el suceso }\end{array}$ \\
\hline $\begin{array}{l}\text { Aislamiento social } \\
\text { Acercamiento a personas inapropiadas } \\
\text { Rechazo de ayuda terapéutica (cuando se necesita) }\end{array}$ & $\begin{array}{l}\text { Búsqueda de apoyo social y familiar } \\
\text { Alejamiento de personas tóxicas } \\
\text { Búsqueda de ayuda terapéutica (cuando se necesita) }\end{array}$ \\
\hline $\begin{array}{l}\text { Conductas autodestructivas: } \\
\text { - Abuso de alcohol y drogas } \\
\text { - Automedicación sin control } \\
\text { - Conductas de riesgo (conducción temeraria, deportes de } \\
\text { riesgo...) } \\
\text { - Conductas violentas }\end{array}$ & $\begin{array}{l}\text { Conductas constructivas: } \\
\text { - Consumo moderado de alcohol } \\
\text { - Medicación controlada (si es necesaria) } \\
\text { - Implicación en conductas gratificantes sin riesgo } \\
\text { - Conductas respetuosas o altruistas con los demás }\end{array}$ \\
\hline \multicolumn{2}{|c|}{ Cognitiva } \\
\hline Atención selectiva a sucesos traumáticos pasados & $\begin{array}{l}\text { Focalización atencional en situaciones actuales positivas o } \\
\text { en proyectos de futuro }\end{array}$ \\
\hline \multicolumn{2}{|c|}{ Emocional } \\
\hline $\begin{array}{l}\text { Anclaje en sentimientos negativos: } \\
\text { - Nostalgia paralizante } \\
\text { - Deseos de venganza e impotencia } \\
\text { - Odio, rencor, resentimiento } \\
\text { - Sentimientos de culpa } \\
\text { - Ira, hostilidad }\end{array}$ & $\begin{array}{l}\text { Sentimientos positivos liberadores: } \\
\text { - Nostalgia positiva } \\
\text { - Perdón, compasión } \\
\text { - Dejar el suceso traumático en manos de la Justicia } \\
\text { (humana o divina) } \\
\text { - Desahogarse emocionalmente con seres queridos }\end{array}$ \\
\hline \multicolumn{2}{|c|}{ Regulación emocional cognitiva } \\
\hline $\begin{array}{l}\text { - Negación } \\
\text { - Catastrofismo } \\
\text { - Rumiación } \\
\text { - Autoculpabilización } \\
\text { - Culpar a otras personas }\end{array}$ & $\begin{array}{l}\text { - Aceptación } \\
\text { - Puesta en perspectiva } \\
\text { - Reevaluación positiva } \\
\text { - Fijarse selectivamente en lo positivo } \\
\text { - Centrarse en la planificación }\end{array}$ \\
\hline
\end{tabular}


información defectuoso y que se ha producido una especie de atracón emocional. Se ha creado en la persona una especie de red de miedo en la memoria. De hecho, son muchos los estímulos que pueden activarla: la noche, la soledad, un ruido incontrolado, algunos lugares o personas, ciertas noticias, los viajes, etcétera. De este modo, las imágenes traumáticas se reproducen involuntaria y repetitivamente en forma de pesadillas y de pensamientos invasivos que escapan al control de la persona tiempo después de haber ocurrido el suceso. Es decir, el pasado traumático actúa invasivamente sobre el presente de la víctima, impidiéndole reanudar una vida cotidiana normalizada y disfrutar con el presente. Estas vivencias traumáticas, más allá de un mero recuerdo, suponen revivir el acontecimiento sufrido con pensamientos e imágenes (personas, luces, sonidos, olores, etcétera), como si estuviese ocurriendo ahora mismo. La intensidad de la vivencia y su carácter impredecible e inevitable generan en la víctima a menudo una sensación de terror (Bryant \& Guthrie, 2007).

La terapia de exposición en estos casos tiene por objetivo facilitar la integración cognitiva y emocional del suceso traumático. El terapeuta confronta al paciente con los recuerdos traumáticos en el contexto de seguridad que ofrece una sesión clínica (lo que facilita la desactivación de la reacción de ansiedad). Con esta estrategia se trata de que la persona sea capaz de guardar los recuerdos en el archivador correspondiente y de poner orden en el caos cognitivo y emocional. De este modo, el paciente puede llegar a controlar los recuerdos, en lugar de que los recuerdos le controlen a él, y evitar la generalización de estímulos. Los objetivos concretos de esta terapia son: a) sustituir la reexperimentación por el recuerdo: no es lo mismo revivir que recordar, por desagradables que sean los recuerdos; y b) diferenciar entre el suceso traumático y otros sucesos que son similares, pero que no son peligrosos. Por ejemplo, un hombre con barba ha sido el responsable de la agresión sexual de la víctima, pero no todos los hombres con barba son peligrosos.

En los seres humanos existe una memoria verbal, que conserva la información, y una memoria emocional, que archiva los iconos y las imágenes de nuestras vivencias emocionales. Al margen de la ansiedad y de la tristeza generadas, recordar y verbalizar lo sucedido en un ambiente de apoyo (la relación terapéutica) facilita la transformación de las imágenes caóticas del trauma, mantenidas en la memoria emocional, en sucesos ordenados espaciotemporalmente bajo el control de la memoria verbal y que tienden a formar parte ya de la biografía de la persona. En cierto modo, se trata de poner nombre a lo que se ha vivido (Echeburúa, 2004; Foa \& Rothbaum, 1998).

De este modo, los recuerdos se reintegran, ya asimilados, en la biografía de una persona y en la visión de sí misma y del mundo que poseía con anterioridad al suceso traumático. Así, los pacientes son capaces de asumir que los recuerdos dolorosos no pueden hacer daño real y de descubrir su propia capacidad para modular sus respuestas de ansiedad. Tal tarea se completa, según las circunstancias, cuando la persona tiene la posibilidad de volver a visitar los lugares y a utilizar objetos relacionados con el suceso doloroso (Foa, Keane, \& Friedman, 2003; Thomaes, Engelhard, Sijbrandij, Cath \& Van den Heuvel, 2016).

\section{Perdón}

A un nivel filogenético, la tendencia humana a perdonar es una cualidad genética favorecida por la fuerza evolutiva de la selección natural porque permite a los miembros de nuestra especie hacer las paces con el ayer, reponerse y perpetuarse (Beristáin, 2004; Enright \& Fitzigibbons, 2000).

La capacidad de perdonar puede ser un ingrediente fundamental en la recuperación de la víctima. No se puede cambiar lo que a una persona le ha ocurrido en la vida, pero sí se puede modificar su mirada y su actitud hacia esos mismos sucesos para reinterpretar su significado de una forma más positiva (Mullet, 2012).

Perdonar no es olvidar, y mucho menos aceptar la conducta abyecta del ofensor: es, sobre todo, librarse del dolor. Perdonar es colaborar conscientemente a que la herida se cicatrice, sin cerrar la herida en falso, y luego aprender a vivir con esa cicatriz. De este modo, el perdón implica la atenuación de emociones, conductas y juicios negativos (Kalayjian \& Paloutzian, 2009; Rocha, Amarís \& López-López, 2017).

Así, el perdón puede tener unos efectos psicológicos positivos: no vivir atormentado por un pasado traumático, mejorar la salud (por ejemplo, dormir mejor, estar más relajado, consumir menos fármacos), reconciliarse consigo mismo y recuperar la paz interior. En cierto modo, perdonar no es hacer ningún favor a nadie, sino hacérselo a uno mismo. Perdonar es sinónimo de liberación. La persona que perdona experimenta una disminución del grado de resentimiento. De este modo, sus comportamientos frente al ofensor se vuelven menos negativos y sus actitudes menos resentidas. Por ello, deshacerse del rencor contribuye a desprenderse de una carga que puede resultar insoportable. El recuerdo sin ira, sin afanes vengativos, alivia el dolor emocional (Kaleta \& Mróz, 2018).

Además, el perdón desempeña un papel adicional: siempre que se perdona a alguien por algún agravio, también aumenta la capacidad de perdón hacia uno mismo. Si se es tolerante con los otros, le resulta a uno más fácil aceptar los propios errores (Beristáin, 2004).

Perdonar puede ser la única posibilidad que posee el ser humano para reelaborar cognitiva y emocionalmente un pasado objetivamente inmodificable. El perdón es una estrategia 
de afrontamiento relacionada con la salud mental y el bienestar (Davis et al., 2016; Toussaint, Shield \& Slavich, 2016), que, entre otros aspectos, posibilita la reducción de los síntomas del trastorno de estrés postraumático (Swan \& Scott, 2009). La fuerza del perdón permite a la persona romper con la irreversibilidad de lo ya sucedido y proyectarla hacia el futuro (Beristáin, 2004).

Otorgar el perdón es más fácil cuando el ofensor muestra arrepentimiento, reconoce el daño causado y presenta disculpas sinceras por el mal generado. Las víctimas presentan diferencias individuales en cuanto a la capacidad de perdón, que es mayor cuando han tenido un modelado familiar a este respecto y cuando cuentan con un estilo cognitivo optimista, una estabilidad emocional previa al suceso y un buen apoyo familiar y social (Mullet, 2012).

\section{Estrategias de afrontamiento no adaptativas}

\section{Nostalgia paralizante}

La nostalgia puede ser considerada como una estrategia de afrontamiento positiva o negativa según las circunstancias. Hay una nostalgia positiva o inocua (la que evoca momentos agradables de la vida y permite avanzar y contrarrestar los sentimientos pasajeros de soledad) y una nostalgia dañina (aquella que paraliza o desmotiva a la persona) (Bohórquez, 2011; Zhou, Sedikides, Wildschut \& Gao, 2008). La nostalgia paralizante es un conjunto de recuerdos agridulces que le pueden anclar a una persona en un pasado idealizado anterior al suceso traumático, anular su presente e hipotecar su futuro. Este tipo de nostalgia, compuesta de distorsiones cognitivas que impiden ver el pasado con exactitud, casi siempre aparece cuando el presente se percibe como desagradable y el futuro resulta amenazante (Trujillo, 2002).

La nostalgia paralizante es una felicidad triste: se recuerda el gozo del pasado anterior al suceso traumático, pero duele saber que todas esas experiencias (la infancia, la presencia de las personas fallecidas, etcétera) ya no pueden volver. En cierto modo, este tipo de nostalgia es como la esperanza al revés: se reproduce mentalmente un pasado más o menos idílico que entristece porque nunca más va a tener lugar (Villa, 2004).

Existe en algunas personas una fuerte propensión a devaluar las ventajas y a magnificar los males del tiempo presente. La instalación en una actitud nostálgica estable, además de generar un elevado gasto de energía psíquica (Bohórquez, 2011), impide la focalización atencional en el presente, así como la adopción de estrategias de afrontamiento adaptativas para superar los recuerdos traumáticos (Echeburúa, 2004).

\section{Odio/rencor/resentimiento}

El odio es un sentimiento de rechazo profundo y de deseo de destrucción de la persona odiada porque nos ha deparado una humillación. Se trata de una respuesta primaria y que puede surgir de forma automática, pero resulta destructora para la víctima porque le impide implicarse en proyectos positivos. Una manera de instigar el odio consiste en hacer creer a una persona que sus males provienen de otras personas. El odio es un sentimiento negativo que solo hace daño a quien lo siente y se vuelve contra uno mismo; a los ofensores no les llega nada de ese odio. El desprecio alivia con frecuencia, pero nunca consuela (Lázaro, 2013).

El rencor afecta a nivel cognitivo (pensamientos de venganza), afectivo (ira) y conductual (distanciamiento o enfrentamiento con el ofensor). El resentimiento y el rencor (la ira contenida), incluso la antipatía o el desprecio, son un odio en tono menor y constituyen una forma de agresión pasiva. El odio se alimenta con la hostilidad percibida hacia otros, a quienes se responsabiliza de los males propios.

El odio es energizante (moviliza grandes emociones), pero el odio enquistado al agresor (el rencor) absorbe la atención, encadena al pasado, impide cicatrizar la herida y, en último término, dificulta la alegría de vivir. Se genera un estado de excitación que puede producir tensión muscular, malestar gastrointestinal, hipertensión y sentimientos de sobrecarga. El odio supone un reconocimiento doloroso de la impotencia ante la persona odiada e incluso culpa y autodesprecio y, por ello, frecuentemente no se confiesa. Al final es una cuestión de supervivencia. Vivir con odio es malo para la salud porque genera más odio y no deja a la persona seguir adelante (Baron-Cohen, 2012).

El odio consta de tres componentes: negación de intimidad (alejamiento emocional del odiado), pasión (rabia intensa) y procesamiento de la información defectuoso (devaluación cognitiva del odiado). El odio impide pensar en las razones del otro y lleva siempre a la minusvaloración de sus creencias y actitudes (Lázaro, 2013).

El resentimiento consiste en sentirse dolido y no olvidar. Es una emoción que corroe por dentro y que una y otra vez tiende a imaginar la forma de dañar al otro. El resentimiento enfermizo está ligado a una especial hipersensibilidad para sentirse herido, dañado, maltratado, lo que lleva a una deformación de la realidad.

\section{Deseos de venganza}

La venganza, que va más allá del odio, consiste básicamente en el desquite contra una persona en respuesta a una mala acción percibida. La venganza es, en realidad, un ajuste de cuentas. El deseo de venganza consiste en forzar a quien haya hecho algo malo a sufrir el mismo dolor que él infligió 
y a asegurarse de que esta persona no volverá a cometer daños otra vez. La venganza es un acto que, en la mayoría de los casos, causa placer a quien la efectúa, debido al sentimiento de rencor que ocasiona el factor antecedente. Sin embargo, es un mecanismo adaptativo negativo que interfiere en el proceso de recuperación de las víctimas (BacaBaldomero, 2014).

En el ser humano anida una tendencia natural a la venganza, que está basada en el recuerdo de cuando se ha sentido agraviado y humillado. Toda víctima, por el mero hecho de serlo, siente un deseo de venganza y no puede evitar el sentirlo. No se debe a una víctima impedir expresar su deseo de venganza. Los sentimientos de venganza son tan psicológicamente necesarios como socialmente inadmisibles. La venganza está excluida de la civilización, pero no se puede suprimir de las emociones de las víctimas. El esquema es el siguiente: la humillación produce rencor y desesperanza y el posterior resentimiento que se instala en la víctima es causante de un intenso deseo de venganza que podría engendrar un acto de violencia, a modo de resarcimiento. La venganza puede ser vivida por la víctima como la única curación posible para su dolor. El resentimiento puede acabar o no en una conducta violenta, pero lo cierto es que siempre empieza en un acto humillante (Gerstenfeld, 2017).

Sin embargo, la venganza, como el odio o el resentimiento, es siempre excesiva y resulta insaciable. Estar anclado en el resentimiento produce una insatisfacción con la sociedad y un empobrecimiento de la vida personal y, en algunos casos, puede intensificar los síntomas de depresión y ansiedad preexistentes. En último término, el odio o la venganza son un mecanismo adaptativo negativo, sobre todo cuando no son fruto de una mera reacción inicial, sino que se mantienen en el tiempo porque se realimentan por parte del propio individuo.

Los rasgos de las personas más predispuestas a implicarse en conductas vengativas son las siguientes: a) malevolencia hacia los demás; b) déficit del control de impulsos en la vida cotidiana; c) reacciones de cólera y de humillación; y d) distancia afectiva o falta de empatía (BacaBaldomero \& Cabanas, 2003).

La renuncia al deseo de venganza es una obligación social inevitable en una sociedad civilizada, pero la negación social de su necesidad psicológica es una segunda agresión. No hay víctima que no quede desgarrada por el conflicto entre la necesidad psicológica de la venganza directa y el imperativo social de resignarse a la acción de la Justicia (Mullet, 2012).

\section{Conductas autodestructivas}

Los recuerdos traumáticos pueden estar, a veces, asociados a sentimientos de culpa que generan un profundo malestar emocional. Las víctimas de sucesos especialmente dolorosos, como el abuso sexual en la infancia, la agresión sexual por una persona conocida o la violencia continuada en la pareja, pueden sentirse culpables por no haber adoptado medidas preventivas, por no haber actuado con la debida contundencia cuando ocurrió el suceso o por no haberse sentido capaces de denunciar al agresor (Echeburúa, 2004).

La confusión generada por un suceso traumático, sobre todo en el caso de personas con rasgos obsesivos, facilita la aparición de sentimientos de culpa y la asunción de una responsabilidad propia en lo ocurrido. El dolor puede combatirse con analgésicos, pero la culpa no (Harder, 1995). De hecho, cuando la culpa y el trauma están relacionados, las víctimas corren el riesgo de estar deprimidas y de mostrar una ideación suicida (Browne, Trim, Myers \& Norman, 2014; Echeburúa, 2015).

El malestar emocional experimentado puede llevar a la persona a implicarse en conductas autodestructivas, como el abuso de alcohol o drogas, la automedicación sin control, la asunción de conductas de riesgo (tales como conducir de forma temeraria o implicarse en deportes de riesgo), el aislamiento social o la práctica de conductas violentas. Todo ello tiene en común el deterioro de la calidad de vida de la persona y la profunda alteración de las relaciones interpersonales sanas (Echeburúa, Corral \& Amor, 2001).

\section{Regulación emocional cognitiva (adaptativa y menos adaptativa)}

El mayor o menor uso de determinadas estrategias de regulación emocional cognitiva puede asimismo condicionar el proceso de recuperación o estar vinculado a diferentes trayectorias de las víctimas ante sucesos potencialmente traumáticos (Crespo \& Fernández-Lansac, 2016).

Así, por ejemplo, el afrontamiento emocional cognitivo basado habitualmente en estrategias tales como la negación, la rumiación, el catastrofismo, la autoculpabilización o la atribución externa de los males propios a los demás está asociado a diversos problemas emocionales, tales como la ansiedad y la sintomatología depresiva, y, en último término, conlleva un peor pronóstico de recuperación (Garnefski \& Kraaij, 2007; Sakakibara \& Kitahara, 2016).

Por el contrario, hay un tipo de afrontamiento emocional cognitivo más adaptativo. Es el caso de las personas que han sido victimizadas y tienden a la aceptación de lo ocurrido, son capaces de ponerlo en perspectiva dentro de su trayectoria vital, reevalúan los posibles aspectos positivos existentes y se centran atencionalmente en la planificación de su vida actual y futura. La recuperación de las personas con este tipo de afrontamiento es mucho más esperanzadora (Kevers, Rober, Derluyn \& De Haene, 2016). 


\section{Resiliencia y crecimiento postraumático}

Las personas que sufren un suceso potencialmente traumático pueden seguir diferentes trayectorias a lo largo del tiempo: disfunción crónica, aparición de síntomas de inicio demorado, recuperación gradual y funcionamiento saludable o resiliencia (Bonanno, 2004; Bonanno \& Mancini, 2012).

Como se puede observar en la vida cotidiana, hay personas que se muestran resistentes a la aparición de síntomas clínicos tras la experimentación de un suceso traumático. Ello no quiere decir que no sufran un dolor subclínico ni que no tengan recuerdos desagradables, sino que, a pesar de ello, son capaces de hacer frente a la vida cotidiana y pueden disfrutar de otras experiencias positivas (Brooks \& Goldstein, 2004).

La resiliencia (la resistencia al estrés y a la adversidad) es la capacidad del ser humano para responder positivamente ante una grave contrariedad, es decir, el proceso de adaptación positiva a sucesos de vida desafiantes o traumáticos. La resiliencia supone la presencia de dos componentes: a) resistir a la adversidad; $\mathrm{y}$ b) transformar las situaciones adversas en oportunidades de desarrollo y crecimiento (Amor \& Echeburúa, 2015; Baroudy, 2011; Cyrulnik, 2013).

Los sucesos traumáticos pueden servir para sacar lo mejor de cada persona. Mucha gente se sorprende de la fortaleza que es capaz de encontrar en una situación de adversidad. En este sentido hay que resaltar el fenómeno del crecimiento postraumático, basado en la capacidad del ser humano de rehacerse frente a los embates de la vida, como si el trauma vivido y asumido hubiera desarrollado en la persona recursos latentes e insospechados que mejoran incluso su funcionamiento anterior. Este crecimiento postraumático puede referirse a tres áreas: a) cambios en uno mismo (aumento en las propias capacidades de afrontamiento); b) cambios en las relaciones interpersonales (fortalecimiento de las relaciones con los verdaderos amigos); y c) cambios en la espiritualidad y en la filosofía de vida (modificación en la escala de valores) (Rojas Marcos, 2010; Tedeschi \& Calhoun, 2004).

En cualquier caso, hay una relación estrecha entre el crecimiento postraumático y el recurso a estrategias de afrontamiento adaptativas (Calhoun \& Tedeschi, 2014; Matsui \& Taku, 2016; Sarasua, Zubizarreta, Corral \& Echeburúa, 2012; Tan, 2013).

\section{Conclusiones}

En resumen, las personas victimizadas no son meras marionetas en manos de sus recuerdos, que deben aprender a modular emocionalmente. Las vivencias dramáticas sufri- das pueden tiranizar a una persona, pero también pueden transformarse en recuerdos dolorosos tolerables que forman parte de su biografía, sin que interfieran negativamente en su vida cotidiana actual y futura. Es decir, se trata de convertir un pasado traumático en un pasado biográfico, de modo que las víctimas no queden atrapadas en el túnel del tiempo y puedan implicarse en un proyecto de vida atractivo (Echeburúa, 2010).

Las vivencias objetivas del pasado son inmodificables, pero la percepción de esas vivencias es cambiable y puede, por ello, transformar el curso de la vida presente. Precisamente el proceso de recuperación de una víctima supone la transformación de las imágenes del trauma que se hallan en la memoria emocional en sucesos ordenados espacio-temporalmente bajo el control de la memoria verbal. Hay algunas actitudes y conductas, como el perdón o el olvido activo (o, en los casos precisos, el tratamiento psicológico de exposición), que facilitan el procesamiento emocional de las vivencias traumáticas; otras, por el contrario, como el odio o la venganza, lo dificultan. A este proceso de convertir las vivencias en recuerdos (memoria dolorosa, pero solo memoria) ayuda el paso del tiempo, la reanudación de la vida cotidiana, la implicación en nuevos proyectos, el soporte familiar y la calidad del apoyo social recibido. Todo ello protege a la persona de los trastornos mentales e incluso del riesgo de suicidio (De la Cruz, 2017; Echeburúa, 2015).

La mayor o menor intensidad de los recuerdos no depende solo de un automatismo psicológico que escape al control del individuo. Hay personas que viven encadenadas al pasado, que se hacen preguntas sin respuesta ("¿por qué me ha pasado esto a mi??"), que intentan volver a lo que ya no existe y que realimentan emociones negativas (odio, venganza, culpa, resentimiento, etcétera). Otras, por el contrario, centran su atención en el presente, sin olvidar las desgracias ocurridas, y se proyectan hacia el futuro, apoyadas en emociones positivas, como la esperanza en el porvenir o el perdón al ofensor (Cyrulnik, 2013).

Solo cuando una persona llega a ser suficientemente libre para volver la vista atrás, pero no desde el punto de vista de un individuo victimizado, sino desde la aceptación plena del pasado, únicamente entonces se muestra capaz de centrar su atención en el presente y de volcarse en proyectos futuros (Rocha et al., 2017).

El perdón es algo que se puede otorgar sin necesidad de que sea solicitado. Es una estrategia individual de supervivencia para deshacerse de las cadenas del odio y descargarse del peso de la venganza. El odio amarga nuestras vidas. Apaciguar la ira tras el daño recibido supone restablecer el equilibrio y ser libre para siempre respecto al hecho o individuo que nos ha herido (Beristáin, 2004).

Por último, las víctimas deben dejar de ser víctimas lo antes posible, como la aspiración de un enfermo es dejar 
de estarlo. La condición de víctima es un estado transitorio que configura un rol pasajero que debe mantenerse solo el tiempo en que los mecanismos adaptativos del individuo (o, en su caso, la ayuda profesional) reparan el malestar emocional sufrido. La identidad de víctima a perpetuidad (la instalación en el sufrimiento o en el victimismo), con un estatus permanente, es contraproducente porque prolonga el duelo de los afligidos y los limita para comenzar un nuevo capítulo de su vida. No se es radicalmente víctima, sino persona superviviente, que es la suma de muchas vivencias. En caso contrario, las víctimas pueden realimentar los recuerdos dolorosos y respirar continuamente por la herida (Baca-Baldomero, 2014; Brooks \& Goldstein, 2004).

\section{Referencias}

Abend, R., Pine, D. S., Fox, N. A. \& Bar-Haim, Y. (2014). Learning and memory consolidation processes of attention-bias modification in anxious and non anxious individuals. Clinical Psychological Science, 2, 620-627. doi:10.1177/2167702614526571

Amor, P. J. \& Echeburúa, E. (2015). Violencia intrafamiliar y resiliencia en niños y adolescentes. En: M. F. Rodríguez, J. M. Morell \& J. Fresneda (Eds.), Manual de promoción de la resiliencia infantil y adolescente (pp. 205-230). Madrid, España: Pirámide.

Baca-Baldomero, E. (2014). Transgresión y perversión. Madrid, España: Triacastella.

Baca-Baldomero, E. \& Cabanas, M.L. (2003). Las víctimas de la violencia. Estudios psicopatológicos. Madrid, España: Triacastella.

Baron-Cohen, S. (2012). Empatía cero. Nueva teoría de la crueldad. Madrid, España: Alianza Editorial.

Baroudy, J. (2011). La fiesta mágica y realista de la resiliencia infantil: manual y técnicas terapéuticas para apoyar y promover la resiliencia de los niños, niñas y adolescentes. Barcelona, España: Gedisa.

Beristáin, A. (2004). Las víctimas y el perdón...: hacia la superación del trauma. En: E. Echeburúa, Superar un trauma. Tratamiento de las victimas de sucesos violentos (pp. 191-199). Madrid, España: Pirámide.

Bohórquez, I. A. (2011). Reflexiones sobre la nostalgia en la inmigración. Aperturas Psicoanalíticas, 37. Recuperado de http://www.aperturas. org/articulos.php?id=0000680\&a=Reflexiones-sobre-la-nostalgiaen-la-inmigracion

Bonanno, G. A. (2004). Loss, Trauma, and Human Resilience: have we underestimated the human capacity to thrive after extremely aversive events? American Psychologist, 59, 20-28. doi:10.1037/0003066X.59.1.20

Bonanno, G. A. \& Mancini, A. D. (2012). Beyond resilience and PTSD: Mapping the heterogeneity of responses to potential trauma. Psychological Trauma: Theory, Research, Practice, and Policy, 4, 74-83. doi:10.1037/a0017829

Brooks, R. \& Goldstein, S. (2004). El poder de la resiliencia. Cómo lograr el equilibrio, la seguridad y la fuerza interior necesarios para vivir en paz. Barcelona, España: Paidós.
Browne, K.C., Trim, R. S., Myers, U. S. \& Norman, S. B. (2015). Trauma-related guilt: Conceptual development and relationship with posttraumatic stress and depressive symptoms. Journal of Traumatic Stress, 28, 134-141. doi:10.1002/jts.21999

Bryant, R.A. \& Guthrie, R. M. (2007). Maladaptive self-appraisals before trauma exposure predict posttraumatic stress disorder. Journal of Consulting and Clinical Psychology, 75, 812-815. doi:10.1037/0022006X.75.5.812

Calhoun, L. G. \& Tedeschi, R. G. (2014). Handbook of posttraumatic growth: Research and practice. New York: Psychology Press.

Crespo, M. \& Fernández-Lansac, V. (2016). Memory and narrative of traumatic events: A literature review. Psychological Trauma: Theory, Research, Practice, and Policy, 8, 149-156. doi:10.1037/tra0000041 Cyrulnik, B. (2013). Sálvate, la vida te espera. Madrid, España: Debate. Davis, D. E., Yang, X., DeBlaere, C., McElroy, S. E., Van Tongeren, D. R., Hook, J. N. \& Worthington, E. J. (2016). The injustice gap. Psychology of Religion and Spirituality, 8, 175-184. doi:10.1037/rel0000042

De la Cruz, M. A. (2017). Factores predictores del impacto psicopatológico en víctimas de agresión sexual. Madrid, España: Ministerio de Sanidad, Servicios Sociales e Igualdad.

Echeburúa, E. (2004). Superar un trauma. Tratamiento de las víctimas de sucesos violentos (pp. 191-199). Madrid, España: Pirámide.

Echeburúa, E. (2010). The challenge of posttraumatic stress disorder prevention: How to survive a disaster? Terapia Psicológica, 28, 147-154. doi:10.4067/S0718-48082010000200002

Echeburúa, E. (2015). Las múltiples caras del suicidio en la clínica psicológica. Terapia Psicológica, 33, 117-126. doi:10.4067/S071848082015000200006

Echeburúa, E. \& Guerricaechevarría, C. (2011). Tratamiento psicológico de las víctimas de abuso sexual infantil intrafamiliar: un enfoque integrador. Behavioral Psychology/Psicología Conductual, 19, 469-486.

Echeburúa, E., Amor, P. J., Sarasua, B., Zubizarreta, I., Holgado-Tello, F.P. \& Muñoz, J. M. (2016). Escala de Gravedad de Síntomas Revisada (EGS-R) del Trastorno de Estrés Postraumático según el DSM5: Propiedades psicométricas. Terapia Psicológica, 34, 111-127. doi:10.4067/S0718-48082016000200004

Echeburúa, E., Corral, P. \& Amor, P. J. (2001). Estrategias de afrontamiento ante los sentimientos de culpa. Análisis y Modificación de Conducta, 27, 905-929.

Enright, R. D. \& Fitzigibbons, R.P. (2000). Helping clients forgive: An empirical guide for resolving anger and restoring hope. Washington: APA.

Foa, E. B., Keane, T. M. \& Friedman, M. J. (2003). Tratamiento del estrés postraumático. Barcelona, España: Ariel.

Foa, E. B. \& Rothbaum, B. O. (1998). Treating the trauma of rape: Cognitive-behavioral therapy for PTSD. New York: Guilford Press.

Garnefski, N. \& Kraaij, V. (2007). The Cognitive Emotion Regulation Questionnaire: Psychometric features and prospective relationships with depression and anxiety in adults. European Journal of Psychological Assessment, 23, 141-149. doi:10.1027/1015-5759.23.3.141

Gerstenfeld, P. B. (2017). Hate crimes: Causes, controls, and controversies. Los Ángeles: Sage. 
Harder, D. W. (1995). Shame and guilt assessment, and relationships of shame — and guilt — proneness to psychopathology. En: J. P. Tangney, K. W. Fischer, J.P. Tangney, K. W. Fischer (Eds.), Self-conscious emotions: The psychology of shame, guilt, embarrassment, and pride (pp. 368-392). New York, NY, US: Guilford Press.

Kalayjian, A. \& Paloutzian, R. F. (2009). Forgiveness and reconciliation: Psychological pathways for conflict transformation and peace building. New York: Springer.

Kaleta, K. \& Mróz, J. (2018). Forgiveness and life satisfaction across different age groups in adults. Personality and Individual Differences, 120, 17-23. doi:10.1016/j.paid.2017.08.008

Kaplan, R. L., Levine, L. J., Lench, H. C. \& Safer, M. A. (2016). Forgetting feelings: Opposite biases in reports of the intensity of past emotion and mood. Emotion, 16, 309-319. doi:10.1037/emo0000127

Kevers, R., Rober, P., Derluyn, I. \& De Haene, L. (2016). Remembering collective violence: Broadening the notion of traumatic memory in post-conflict rehabilitation. Culture, Medicine and Psychiatry, 40, 620-640. doi:10.1007/s11013-016-9490-y

Kuehl, L.K., Wolf, O. T., Driessen, M., Schlosser, N., Fernando, S.C. $\&$ Wingenfeld, K. (2017). Effects of cortisol on the memory bias for emotional words? A study in patients with depression and healthy participants using the Directed Forgetting task. Journal of Psychiatric Research, 92, 191-198. doi:10.1016/j.jpsychires.2017.04.012

Lázaro, J. (2013). La violencia de los fanáticos. Madrid, España: Triacastela. Matsui, T. \& Taku, K. (2016). A review of posttraumatic growth and help-seeking behavior in cancer survivors: Effects of distal and proximate culture. Japanese Psychological Research, 58 142-162. doi:10.1111/jpr.12105

Mitchell, A.P. (2015). Autobiographical memory response to a negative mood in those with/without a history of depression. Studia Psychologica, 57, 229-241.

Mullet, E. (2012). Perdón y terapia. En: F. J. Labrador, \& M. Crespo (Eds.), Psicología clínica basada en la evidencia (pp. 137-152). Madrid, España: Pirámide.

Picó -Alfonso, M. A., Echeburúa, E. \& Martínez, M. (2008). Personality disorder symptoms in women as a result of chronic intimate male partner violence. Journal of Family Violence, 23, 577-588. doi:10.1007/ s10896-008-9180-9

Rocha, A., Amarís, M. \& López-López, W. (2017). El perdón como estrategia de afrontamiento. Una mirada desde el modelo de la complejidad del afrontamiento. Terapia Psicológica, 35, 271-281.

Rojas Marcos, L. (2010). Superar la adversidad. El poder de la resiliencia. Madrid, España: Espasa.

Sakakibara, R. \& Kitahara, M. (2016). The relationship between Cognitive Emotion Regulation Questionnaire (CERQ) and depression, anxiety: Meta-analysis. The Japanese Journal of Psychology, 87, 179-185.

Sarasua, B., Zubizarreta, I., Corral, P. \& Echeburúa, E. (2012). Factores de vulnerabilidad y de protección del impacto emocional en mujeres adultas víctimas de agresiones sexuales. Terapia Psicológica, 30, 7-18. doi:10.4067/S0718-48082012000300002
Swan, A. H. \& Scott, C. (2009). Complicated grief: Implications for the treatment of post-traumatic stress disorder in couples. Sexual and Relationship Therapy, 24, 16-29. doi:10.1080/14681990802641299

Tan, S. (2013). Resilience and posttraumatic growth: Empirical evidence and clinical applications from a Christian perspective. Journal of Psychology and Christianity, 32, 358-364.

Tedeschi, R. G. \& Calhoun, L. G. (2004). Target Article: 'Posttraumatic Growth: Conceptual Foundations and Empirical Evidence'. Psychological Inquiry, 15 1-18. doi:10.1207/s15327965pli1501_01

Thomaes, K., Engelhard, I. M., Sijbrandij, M., Cath, D.C. \& Van den Heuvel, O. A. (2016). Degrading traumatic memories with eye movements: a pilot functional MRI study in PTSD. European Journal of Psychotraumatology, 7, 31371. doi:10.3402/ejpt.v7.31371

Tielman, M. L., Neerincx, M. A., Bidarra, R., Kybartas, B. \& Brinkman, W. (2017). A therapy system for post-traumatic stress disorder using a virtual agent and virtual storytelling to reconstruct traumatic memories. Journal of Medical Systems, 41, 125. doi:10.1007/s10916-017-0771-y

Toussaint, L.L., Shields, G. S. \& Slavich, G. M. (2016). Forgiveness, stress, and health: A 5-week dynamic parallel process study. Annals of Behavioral Medicine, 50, 727-735. doi:10.1007/s12160-016-9796-6

Trujillo, M. (2002). Psicología para después de una crisis. Madrid, España: Aguilar.

Uzer, T. \& Brown, N.R. (2017). The effect of cue content on retrieval from autobiographical memory. Acta Psychologica, 172, 84-91. doi:10.1016/j.actpsy.2016.11.012

Villa, I. (2004). Saber que se puede. Recuerdos y reflexiones de una víctima de terrorismo. Barcelona, España: Martínez Roca.

Zhou, X., Sedikides, C., Wildschut, T. \& Gao, D. (2008). Counteracting loneliness: On the restorative function of nostalgia. Psychological Science, 19, 1023-1029. doi:10.1111/j.1467-9280.2008.02194.x 